\title{
Invasive Alien Species Management: A Personal Impasse
}

\author{
Graham Epstein ${ }^{1,2 *}$ \\ ${ }^{1}$ Marine Biological Association of the United Kingdom, Plymouth, United Kingdom, ${ }^{2}$ Ocean and Earth Science, National \\ Oceanography Centre Southampton, University of Southampton, Southampton, United Kingdom
}

Keywords: invasive, alien species, environmental impact, community ecology, environmental management

Over the last few years there has been a surge in publications regarding the sociology of invasive alien species (IAS). One review discussed how IAS management projects often lead to social conflicts (Crowley et al., 2017), while another suggested that culture may influence our moral standpoint on biodiversity conservation (Dickman et al., 2015). Other publications have focused on the perceptions of IAS impacts and even suggest the rise of IAS denialism (Lidstrom et al., 2015; Russell and Blackburn, 2017b). This has hopefully been constructive and progressive for both science and policy. However, IAS impact is a particularly emotive subject, and decisions can be strongly influenced by individual standpoints and perceptions. Here, I highlight my personal impasse on IAS management and show how individual perceptions may influence management actions.

Considering myself first and foremost to be a conservationist and environmentalist, I feel that the effects of all IAS should be considered detrimental due to alteration of the natural environment and intrinsic competition with native species. As stated by Russell and Blackburn (2017a) "Alien species must have impacts on the recipient ecosystem simply by their presence (i.e., on the availability of space, food, water, or other resources for other species)." So my stance is that the introduction of all IAS should be prevented while the spread and proliferation of all established IAS should be managed.

But I am also actively working on IAS ecology and have experience working in environmental management. Therefore, I am swayed by reason, evidence, and pragmatism. Although we may like to control all IAS, the full prevention of new introductions across all biomes is an insurmountable aim (Seebens et al., 2017) while the management of already introduced or established IAS is often technically challenging, time consuming, and costly (Courchamp et al., 2017). Due to environmental managers having a limited resource, the hundreds of IAS within each of their jurisdictions and the inevitably of that number increasing, some sort of prioritization process is clearly needed (McGeoch et al., 2016).

It is well-documented that IAS can have conspicuous and major detrimental impacts on biodiversity, excluding or limiting many native species and greatly altering ecosystems (Early et al., 2016). However in other cases, IAS are not thought to be primary drivers of ecological change. This may occur when the IAS is found only in disturbed or modified environments, or where they are able to fill a niche that was not fully utilized by native species (MacDougall and Turkington, 2005). Native species can also benefit from IAS if they provide habitat, trophic subsidy, or competitive and predatory release (Schlaepfer et al., 2011). Although this is still a human-induced change to the environment and therefore could be deemed negative, the facilitative effect of the IAS could have conservation benefit if it contributes to restoration of native habitats, functionally replaces a limited or extinct native species or facilitates a species of high conservation value (Schlaepfer et al., 2011). Therefore, in some cases, I also feel that it would be appropriate to accept certain IAS as our own and not subject them to targeted management.

I also understand those who consider IAS management in a humanistic or anthropocentric perspective. IAS affect a wide variety of industries including agriculture/aquaculture, transport and shipping, water provision systems, and energy generation. For example, an estimate of total 
economic cost in the USA is $\$ 128$ billion per year (Pejchar and Mooney, 2009). However, some IAS can have commercial value as food or materials, and therefore may be economically beneficial (Pejchar and Mooney, 2009). The natural world also provides humans many other ecosystem services including climate and environmental regulation, health, and culture, all of which can also be detrimentally impacted by IAS (Pejchar and Mooney, 2009). As expected, some IAS can also benefit ecosystem services if they are currently lacking from native species or are enhanced by the IAS (Pejchar and Mooney, 2009). From a humanist perspective it is arguable that we should only concentrate on those IAS that cause economic or ecosystem service net loss.

The only way to preclude impact is to prevent IAS arriving through the control of introduction vectors. Stringent biosecurity measures to greatly reduce IAS introductions have long been established and are highly successful in minimizing IAS impact in countries such as Australia and New Zealand (Simberloff et al., 2013; Genovesi et al., 2015). Other countries and regions are starting to follow suit (Genovesi et al., 2015). However, to stem the tide of IAS introductions, better biosecurity legislation, and enforcement is needed across the world (Simberloff et al., 2013; Genovesi et al., 2015).

As no biosecurity measure is a perfect prevention, we must still consider those species that will become IAS in future, as well as those that have already been introduced. For these species I still don't know where I stand-as an environmentalist we should manage all IAS, as a scientist we should manage some, and as a humanist we should manage very few. In order to design the best strategies to manage IAS impact as a whole, objective and clear prioritization processes are needed (McGeoch et al., 2016). I do

\section{REFERENCES}

Barney, J. N., Tekiela, D. R., Dollete, E. S. J., and Tomasek, B. J. (2013). What is the "real" impact of invasive plant species? Front. Ecol. Environ. 11:120. doi: $10.1890 / 120120$

Courchamp, F., Fournier, A., Bellard, C., Bertelsmeier, C., Bonnaud, E., Jeschke, J. M., et al. (2017). Invasion biology: specific problems and possible solutions. Trends Ecol. Evol. (Amst). 32, 13-22. doi: 10.1016/j.tree.2016. 11.001

Crowley, S. L., Hinchliffe, S., and McDonald, R. A. (2017). Conflict in invasive species management. Front. Ecol. Environ. 15, 133-141. doi: 10.1002/fee.1471

Dickman, A., Johnson, P. J., Van Kesteren, F., and MacDonald, D. W. (2015). The moral basis for conservation: how is it affected by culture? Front. Ecol. Environ. 13, 325-331. doi: 10.1890/140056

Early, R., Bradley, B. A., Dukes, J. S., Lawler, J. J., Olden, J. D., Blumenthal, D. M., et al. (2016). Global threats from invasive alien species in the twenty-first century and national response capacities. Nat. Commun. 7:12485. doi: $10.1038 /$ ncomms 12485

Genovesi, P., Carboneras, C., Vilà, M., and Walton, P. (2015). EU adopts innovative legislation on invasive species: a step towards a global response to biological invasions? Biol. Invasions 17, 1307-1311. doi: $10.1007 /$ s10530-014-0817-8

Lidstrom, S., West, S., Katzschner, T., Perez-Ramos, M. I., and Twidle, H. (2015). Invasive narratives and the inverse of slow violence: alien species in science and society. Environ. Hum. 7, 1-40. doi: 10.1215/22011919-3616317

MacDougall, A. S., and Turkington, R. (2005). Are invasive species drivers or passengers of change in degraded ecosystems. Ecology 86, 42-55. doi: 10.1890/04-0669

McGeoch, M. A., Genovesi, P., Bellingham, P. J., Costello, M. J., McGrannachan, C., and Sheppard, A. (2016). Prioritizing species, pathways, and sites to not envy environmental managers that must consider all social, environmental, and economic aspects in order to prioritize and justify their actions; especially as there is a general consensus within IAS management that rapid response greatly increases likelihood of success (Early et al., 2016). Determining where a particular IAS sits on the discussed spectra of impact requires complex experimentation and calculation, taking considerable expenditure and time (Barney et al., 2013). Gaining a full understanding of the impact is often not possible before priorities on management have to be set.

A major factor that has been highlighted by two recent reports, published by academics and environmental managers in the UK, USA, and Australia, is that we must consider the less subjective issue of what management is actually feasible-the likely effectiveness, practicality, risk, cost, impact, and timeframe of management options. I would consider that only then can all the other factors be examined to determine which IAS would be best to prioritize for eradication or control and which, perhaps, should be granted citizenship.

\section{AUTHOR CONTRIBUTIONS}

The author confirms being the sole contributor of this work and approved it for publication.

\section{FUNDING}

GE is funded by the National Environmental Research Council (NERC) Doctoral Training Partnership SPITFIRE (NE/L002531/1), administered through Southampton University.

achieve conservation targets for biological invasion. Biol. Invasions 18, 299-314 doi: 10.1007/s10530-015-1013-1

Pejchar, L., and Mooney, H. A. (2009). Invasive species, ecosystem services and human well-being. Trends Ecol. Evol. (Amst). 24, 497-504. doi: 10.1016/j.tree.2009.03.016

Russell, J. C., and Blackburn, T. M. (2017a). Invasive alien species: denialism, disagreement, definitions, and dialogue. Trends Ecol. Evol. (Amst). 32, 312-314. doi: 10.1016/j.tree.2017.02.005

Russell, J. C., and Blackburn, T. M. (2017b). The rise of invasive species denialism. Trends Ecol. Evol. (Amst). 32, 3-6. doi: 10.1016/j.tree.2016.10.012

Schlaepfer, M. A., Sax, D. F., and Olden, J. D. (2011). The potential conservation value of non-native species. Conserv. Biol. 25, 428-437. doi: 10.1111/j.1523-1739.2010.01646.x

Seebens, H., Blackburn, T. M., Dyer, E. E., Genovesi, P., Hulme, P. E., Jeschke, J. M., et al. (2017). No saturation in the accumulation of alien species worldwide. Nat. Commun. 8:14435. doi: 10.1038/ncomms14435

Simberloff, D., Martin, J. L., Genovesi, P., Maris, V., Wardle, D. A., Aronson, J., et al. (2013). Impacts of biological invasions: what's what and the way forward. Trends Ecol. Evol. 28, 58-66. doi: 10.1016/j.tree.2012.07.013

Conflict of Interest Statement: The author declares that the research was conducted in the absence of any commercial or financial relationships that could be construed as a potential conflict of interest.

Copyright (C) 2017 Epstein. This is an open-access article distributed under the terms of the Creative Commons Attribution License (CC BY). The use, distribution or reproduction in other forums is permitted, provided the original author (s) or licensor are credited and that the original publication in this journal is cited, in accordance with accepted academic practice. No use, distribution or reproduction is permitted which does not comply with these terms. 